\title{
FEASIBILITY OF REAL-TIME REMOTE SPEED ENFORCEMENT FOR WORK ZONES
}

\author{
By \\ Michael D. Fontaine \\ Associate Transportation Researcher \\ Texas Transportation Institute \\ Texas A\&M University \\ 3135 TAMU \\ College Station, TX 77843-3135 \\ Phone: (979) 845-9929 \\ Fax: (979) 845-6006 \\ E-mail:m-fontaine@ tamu.edu \\ Steven D. Schrock \\ Graduate Assistant Researcher \\ Texas Transportation Institute \\ Phone: (979) 845-2489 \\ E-mail:s-schrock@ttimail.tamu.edu \\ Gerald Ullman, Ph.D., P.E. \\ Program Manager \\ Texas Transportation Institute \\ Phone: (979) 845-9907 \\ E-mail: g-ullman@tamu.edu
}

Paper prepared for the $81^{\text {st }}$ Annual Meeting of the

Transportation Research Board

Washington, D.C.,

January 2002

November 2001

\section{Word Count}

Abstract: 249

Body: 5450

Figures: $3 \times 250=750$

Tables: $4 \times 250=1000$

Total: 7449 


\begin{abstract}
Studies have shown that a large percentage of vehicles involved in work zone crashes are traveling at excessive speeds. While traditional speed enforcement has been shown to reduce speeds through the work area, enforcement under these conditions can potentially be dangerous to both the motoring public and enforcement officers. The work zone layout often limits the locations where an officer can set up to enforce the speed limit and the locations where violators can be stopped. Automated speed enforcement technology could help eliminate the need to stop violators in a work zone, but it is not currently a popular concept in the United States due to concerns about motorist privacy. TTI researchers hypothesized that this technology could possibly be useful for work zone enforcement if adapted to more of a real-time operation. This paper summarizes the initial testing of the concept of remote speed enforcement. An automated speed enforcement system (consisting of digital video and lidar technology) was meshed with a wireless communications system. The unit determined when vehicles were exceeding a certain speed threshold. If a vehicle was detected as exceeding the threshold, a digital photograph was taken of the violator. This photograph was then transmitted to an observer stationed downstream of the site. The technical feasibility of the system was assessed through field tests. Focus groups of law enforcement personnel were used to determine potential acceptance of the system in the law enforcement community. Recommendations for future improvements and possible applications of the system are made.
\end{abstract}




\section{INTRODUCTION}

Approximately 770 fatal crashes occurred in work zones nationwide in 1999 (1). Over 30 percent of these crashes involved at least one vehicle that was either traveling over the posted speed limit or at a speed that was deemed unsafe for current conditions (1). Traditional work zone signing specified by the Manual on Uniform Traffic Control Devices as well as reduced regulatory speed limit signing have not been shown to significantly reduce the mean speed of traffic traveling through a work zone (2)

Agencies have tried a variety of techniques to improve work zone safety by reducing speeds. The use of law enforcement has been shown to consistently produce the largest speed reductions (2,3). When law enforcement officers are present, mean speeds can be reduced anywhere between 3 to 25 percent (2). Agencies and motorists are familiar with the use of law enforcement officers to enforce the speed limit, and law enforcement also offers the advantage of being easy to set up and remove. If a work zone is frequently enforced, some speed reduction benefits may carry over into periods where enforcement is not present (3).

Law enforcement personnel face a number of challenges when they attempt to enforce work zone speed limits. Limited lateral space, limited sight distance, and the presence of barriers can make it difficult for law enforcement officers to detect, pursue, and apprehend violators within the confines of the work zone. If officers attempt to apprehend a violator within the work zone, there must be an area where they can safely write a citation and move back into the traffic stream when they have finished citing the violator. In many cases, shoulders or enforcement pull-off areas are not available. In these cases, drivers may not know how to react when an officer attempts to pull them over in a work zone. They may exit onto a side street, wait to pull onto the shoulder until the end of the work zone, or actually stop in the travel lane. If the violator does something unexpected, this could create further safety concerns.

Anecdotal evidence suggests that there are widespread problems enforcing work zone speeds. In fact, "off-the-record" comments from field officers suggest that some work zones may actually receive less enforcement than other sections of road due to these difficulties. The ability of law enforcement to adequately patrol all roads is often limited, so the officers tend to focus their efforts on sections of road where they can most easily and effectively enforce the speed limit.

This paper documents the results of a study of a real-time, remote speed enforcement system for work zone applications. The remote speed enforcement system uses an automated speed enforcement system to photograph images of vehicles violating the speed limit within an actual work zone. The images are then transmitted to an officer stationed downstream of the work zone location. The officer uses these images to identify violators after they have left the work zone, allowing the officer to enforce the speed limit from a safer location. The purpose of this system is not to eliminate the use of officers to enforce the speed limit (as in automated speed enforcement), but to use technology to make it safer for an officer to perform their duties. This paper summarizes the potential technological and legal issues associated with remote speed enforcement, and contrasts remote speed enforcement to automated speed enforcement.

\section{Automated Speed Enforcement}

Automated speed enforcement (ASE) is one possible approach to reducing some of the safety issues related to work zone speed enforcement. Vehicle speeds can be detected using a variety of technologies, including radar, lidar, elapsed travel time measurements, or in-pavement sensors. Most automated speed enforcement systems utilize a radar or lidar unit that is either aimed 
across a road or directly at oncoming traffic. When a vehicle crosses through the radar/lidar beam of an ASE system while traveling above a preset speed threshold, a photograph is taken of the vehicle's license plate. Photos of the driver are taken if needed for evidentiary reasons. In a typical ASE application (such as is done in Europe), these photographs are mailed along with the traffic citation to the registered owner of the vehicle. Theoretically, the ASE system offers the potential to act as a deterrent in much the same way as a law enforcement officer, but also offers a chance to improve safety within the work zone since officers would not have to pursue offenders within the work zone.

\section{Effectiveness}

ASE has been used as a speed control and enforcement tool by over 40 countries around the world, with some systems having been in place for up to 30 years (4). Although no studies of the impact of ASE on speeds in work zone were located, numerous studies of the effectiveness of ASE units on residential roads and freeways indicate that automated enforcement could have a positive impact on speeds and safety at work zones.

ASE has been used extensively in Europe for a number of years. In 1978, ASE units were installed on a high-accident portion of the German autobahn (5). Following the installation of the ASE system, $85^{\text {th }}$ percentile speeds dropped by $45 \mathrm{~km} / \mathrm{h}(28 \mathrm{mph})$. The yearly number of accidents was also reduced after the system was installed (4). A study in the Netherlands evaluated the effects of ASE when combined with variable message sign warnings (6). This study found that average speeds were reduced by $5 \mathrm{~km} / \mathrm{h}(3 \mathrm{mph})$ and the $85^{\text {th }}$ percentile speeds were reduced by $8 \mathrm{~km} / \mathrm{h}(5 \mathrm{mph})$. The percent of vehicles speeding declined by 27 percent after the system was installed. Norway began using ASE in 1988 and now has units on $336 \mathrm{~km} \mathrm{(209}$ $\mathrm{mi}$ ) of road (7). The number of injury accidents on the portions of road with the ASE systems declined an average of 20 percent, and the total number of accidents on these sections declined between 5 and 26 percent.

Canada and Australia have both used ASE in order to address speeding concerns (5). In Ontario, a one-year ASE pilot program reduced the number of vehicles exceeding the speed limit by 50 percent. The number of vehicles traveling at more than $40 \mathrm{~km} / \mathrm{h}(25 \mathrm{mph})$ over the speed limit was reduced by 74 percent. In Australia, the percent of traffic exceeding the speed threshold for enforcement fell from 10.8 percent to 2.4 percent after the ASE system was implemented.

ASE systems are not used widely in the United States, primarily due to legal and political barriers. In 1998, ASE was used in only four states: Arizona, California, Colorado, and Oregon (8). The primary application of ASE in the United States has been at the local level, since local government can more easily create a legal framework that allows the use of ASE. In all locations where ASE has been implemented in the U.S., violations are treated as civil rather than criminal infractions. Legal provisions exist whereby if the owner is not the driver of the vehicle when it is photographed, the owner can identify the driver and avoid the fine.

Paradise Valley, Arizona uses a mobile ASE unit that is positioned in an attended, marked police vehicle. Signs warning of the presence of photo radar are placed at the entrances of neighborhoods and just upstream of the current position of the system (4). The citation rate is approximately 19 times that of mobile police patrols. City officials say the speeds on most roads have decreased, but no speed data was found to substantiate these claims.

Riverside, California has used ASE since mid-1991 and recently performed a study to determine the impact of the system on speeds adjacent to and downstream of the ASE unit (9). 
The effectiveness of photo radar was evaluated on several collector roads with a posted speed limit of $40 \mathrm{~km} / \mathrm{h}(25 \mathrm{mph})$ and a traffic volume of less than 10,000 vehicles per day. The photo radar van produced average speed reductions of $8.2 \mathrm{~km} / \mathrm{h}(5.1 \mathrm{mph})$ alongside the ASE system and $6.6 \mathrm{~km} / \mathrm{h}(4.1 \mathrm{mph})$ about $305 \mathrm{~m}$ (1000 feet) downstream of the site. The photo radar reduced the percentage of vehicles traveling more than $16 \mathrm{~km} / \mathrm{h}(10 \mathrm{mph})$ over the posted speed limit from 52.1 percent to 21.9 percent.

While most American applications have occurred on relatively low-speed urban roads, a study conducted by Lynn, et al. evaluated the effectiveness of photo radar for use on high speed, high volume facilities (10). The most efficient ASE system detected and adequately photographed only 2.4 percent of vehicles exceeding the speed limit, which translated into 65 citations/hour. Although these systems only captured a very small portion of the total number of vehicles exceeding the speed threshold, the least efficient model still outperformed a police officer's capabilities.

\section{Legal Issues}

While automated enforcement may be a potential method of enforcing work zone speed limits, there are a number of legal obstacles that may make it difficult to implement these systems in the United States. The identity of the registered owner of the vehicle can be determined by matching the license plate of the offending vehicle to state motor vehicle records. However, it is necessary to identify the driver of the vehicle in order to issue a citation, and the registered owner may or may not be the driver of the vehicle. If the registered owner is not the driver, the owner will have to be asked to identify the driver of the vehicle, which may presents some legal difficulties (11). If the owner is unwilling to identify the driver, the only viable recourse to compel the owner to identify the driver is to hold them in contempt of court. In many states, people cannot be compelled to testify against their spouse, which could limit the ability of the courts to enforce ASE violations (11).

The right to privacy may also be an issue. However, at least one state general counsel has suggested that behavior that is readily observable on a public street is not protected by the right to privacy under the U.S. Constitution (11). Nonetheless, several jurisdictions require an officer to actually witness an infraction in order to write a speeding citation. Statutory changes may be needed that would provide for certification of the equipment to self-authenticate ASE photographs (11).

\section{Social Issues}

Although the right to privacy does not appear to be a major barrier to the use of ASE from a legal perspective, the public may perceive that the use of these systems as an invasion of their privacy. Many citizens also believe that automated enforcement systems are purely revenue generators, with limited benefit to safety. In fact, many citizens may equate the use of cameras for speed or red light enforcement as being the first step for "Big Brother" to be able to monitor their every move (12). Even in Europe, where ASE systems have been used for decades, citizens are concerned about the issues of privacy, and ASE installations may be seen primarily as revenue generators (13). Given these concerns, it would appear that the public's attitudes toward automated enforcement would need to dramatically change before it becomes practical to use these systems in the United States. 


\section{Summary}

While automated speed enforcement would offer the potential to enforce speed limits effectively and safely within the work zone, current legal and social barriers will probably prevent the widespread use of ASE in the near future. However, by using a combination of automated speed enforcement technology with an officer downstream of the work site, it may be possible to improve the safety of the officer and eliminate some of the legal obstacles associated with automated enforcement in work zones. To test the technical feasibility of this hypothesis, researchers at the Texas Transportation Institute (TTI) developed and field-tested what they termed a prototype "remote speed enforcement system."

\section{OBJECTIVES AND SCOPE}

This project investigated the feasibility of using remote enforcement in work zones. The primary purpose of this evaluation was to determine if the remote enforcement concept appeared to be promising enough to warrant further development. The following objectives were established for this project:

- Determine whether a remote enforcement system was technically feasible;

- Assess whether vehicles could be correctly identified downstream; and

- Determine attitudes towards the system from the law enforcement community.

\section{REMOTE ENFORCEMENT CONCEPT}

The prototype system was developed using off-the-shelf technology. The remote speed enforcement unit consists of the following four major components:

- $\quad$ speed detection system,

- vehicle imaging system,

- wireless communications system, and

- downstream viewing system.

The system photographs vehicles that exceed a predetermined speed threshold approaching or within the work zone. Pictures of violators are then transmitted to a laptop computer stationed at a downstream location (presumably one that would allow for safe enforcement activities to be performed). The distance between the laptop and the speed detection and imaging station must be sufficient to allow time for data transmission, but not so long as to hamper offender identification at the downstream location. Since the concept would actually have an officer still present to actually issue citations, this system could be legally viable under existing laws in many jurisdictions.

\section{Speed Detection and Vehicle Imaging System}

For the prototype system developed for this project, a commercially available ASE system provided the basic technology to capture images of vehicles exceeding the speed limit. The system is intended to be a stand-alone system used for automated speed enforcement. It consists of a lidar gun mounted on top of a high resolution digital camera with a $300 \mathrm{~mm}$ lens. Figure 1 shows the lidar and camera provided. By using a lidar gun, the ASE system can accurately determine the speed of an individual vehicle. This system is connected to a computer that runs a 
proprietary data acquisition program and stores digital images of violators. Two programs were provided by the manufacturer:

- a data capture program that allowed the user to set parameters such as speed threshold, image brightness, and the range during which images should be taken, and

- A viewer program that allows images to be viewed with speed and location information superimposed on the picture.

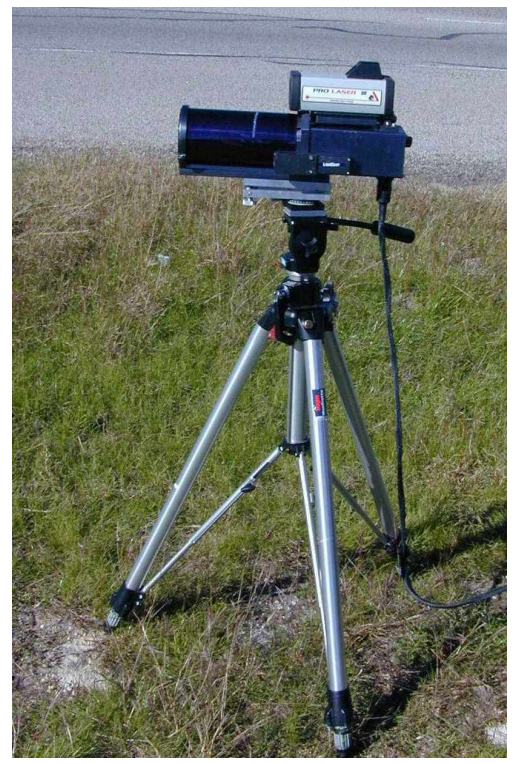

Figure 1. Automated Speed Enforcement System Lidar and Camera.

The data capture program shows real-time video of the vehicles passing through the camera's view, while the viewer program only shows the still image files that were captured by the system. Pictures are only taken of vehicles that exceed the user-defined speed threshold. Depending on the distances specified by the user for data collection, sometimes multiple images of the same vehicle may be collected. The images collected by the ASE system can be stored as black and white JPEG or bitmap files. Figure 2 shows the image file as displayed by the viewer program. Encryption software developed by the vendor prevents users from manipulating the stored JPEG or bitmap images. 


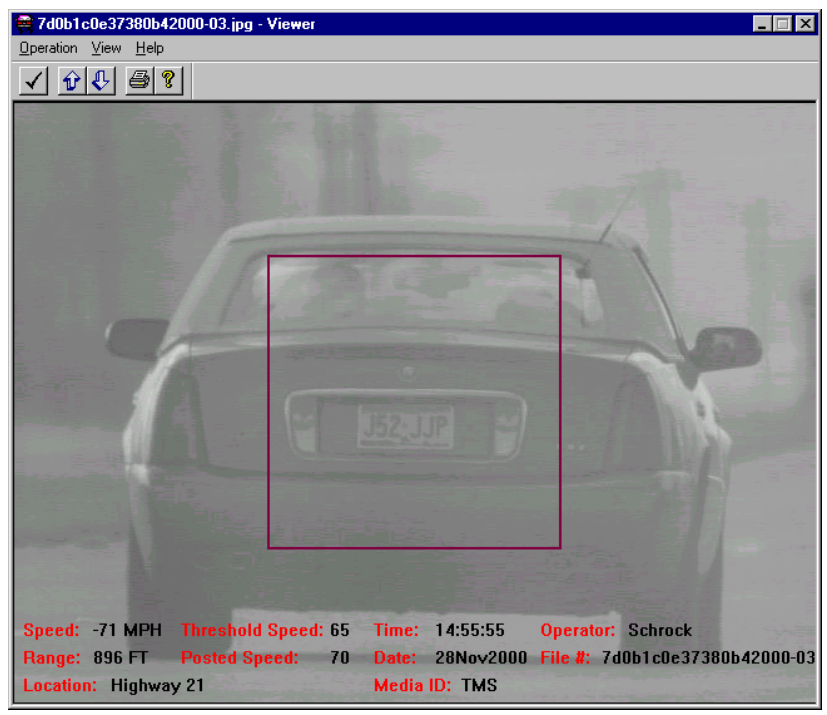

Figure 2. Sample Picture.

\section{Wireless Communications System}

Spread spectrum Ethernet routers were used to provide communication between the camera and the downstream laptop location. The routers used an Ethernet connection to wirelessly transmit data using the TCP/IP protocol. The wireless routers were connected to the computers at the upstream camera position and the downstream observation site. The stated maximum range of the routers was approximately $3.2 \mathrm{~km}$ ( 2 miles). Theoretically, repeater stations could be used to extend the distance from the camera and the downstream laptop receiver as much as needed. However, for this demonstration, no repeater stations were employed.

\section{Downstream Viewing System}

The downstream viewing system consisted of a commercial laptop. TTI developed two pieces of software to allow the laptop computer to communicate with the upstream camera system. First, a data transfer program was developed for use on the upstream camera computer. This program checked a directory every 3 seconds to see if new images were present. If a new image was located, it was transmitted to the downstream computer, and then moved into a different directory.

A data reception program was also developed for use on the downstream laptop. This program provided an audio signal when a new image was present. When a new image arrives, the user presses the "Launch Viewer" button to start the developer's proprietary software, which allows the user to see an image similar to Figure 2.

\section{METHODOLOGY}

Data were collected in two phases. First, the system was tested at four field sites. This portion of the study was intended to identify any technical obstacles with using the system and to assess whether the system could be used to identify vehicles downstream of the camera site. Second, a series of focus group meetings with law enforcement officers was held. This was done in order to determine whether the law enforcement community believed this device would be beneficial for work zone speed enforcement. 


\section{Field Data Collection}

The purpose of the field evaluation was to determine whether implementation of the system was practical. Testing was performed to identify potential operational limitations and determine areas where the system could be improved. The specific goals of the field evaluation were to determine:

- Maximum effective data transmission range,

- Ability of observers to correctly match images to vehicles, and

- Impact of volume of traffic data transmission.

The system was tested at four sites in Brazos County, Texas. All sites were four-lane divided highways with $113 \mathrm{~km} / \mathrm{h}(70 \mathrm{mph})$ speed limits. However, for the sake of simplicity, the sites chosen were not located in actual operating work zones. For the purposes of validating the concept of remote enforcement, the system was tested on regular roadways. It is expected that the findings regarding system performance could be easily extended to work zones, however. Table 1 summarizes the characteristics of the sites.

TABLE 1: Data Collection Site Characteristics.

\begin{tabular}{lccccccc} 
& & & & Threshold & \multicolumn{3}{c}{ Total Volume } \\
\cline { 6 - 8 } \multicolumn{2}{c}{ Location } & Direction & Date & $\begin{array}{c}\text { Speed } \\
\text { km/h }\end{array}$ & $\begin{array}{c}\text { Right } \\
\text { Lane }\end{array}$ & $\begin{array}{c}\text { Left } \\
\text { Lane }\end{array}$ & Total \\
\hline Site 1 & SH 47 & SB & $11 / 10 / 00$ & $105(65)$ & 211 & 73 & 284 \\
Site 2 & SH 47 & SB & $11 / 14 / 00$ & $105(65)$ & 92 & 20 & 112 \\
Site 3 & SH 21 & WB & $11 / 21 / 00$ & $85(55)$ & 566 & 501 & 1067 \\
Site 4 & SH 21 & WB & $11 / 28 / 00$ & $105(65)$ & 232 & 118 & 350 \\
\hline
\end{tabular}

The threshold speed in Table 1 refers to the minimum speed that a vehicle must be traveling in order to be photographed. At sites 1,2, and 4 the threshold speed was set at $8 \mathrm{~km} / \mathrm{h}(5 \mathrm{mph})$ below the posted speed limit. At site 3 , the threshold speed was set at $24 \mathrm{~km} / \mathrm{h}$ (15 mph) below the posted speed limit. In an actual enforcement application, speed thresholds would be set higher than the posted speed limit. Speed thresholds were set below the posted speed in order to facilitate data collection.

The system was located on the right-hand shoulder at each site. All sites were relatively flat, and the camera was typically aimed between 183 and $244 \mathrm{~m}$ (600 and 800 feet) upstream of the ASE camera installation. If a vehicle was traveling over the speed limit in this range of distances, it photograph was taken. Figure 3 shows a typical remote enforcement installation. All data were collected during dry, clear days. 


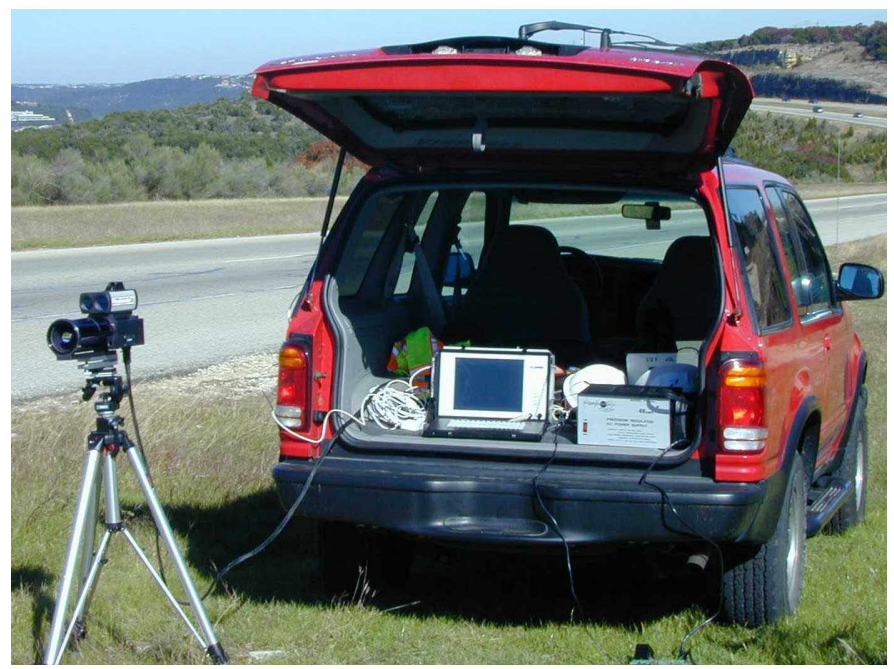

Figure 3. Typical Remote Enforcement Setup.

The photo-lidar system was extremely directional, and could only photograph one lane of traffic at a time. All vehicles photographed were in the right hand travel lane. Researchers made several attempts to photograph vehicles in the left hand travel lane, but the interference from vehicles in the right hand travel lane proved to make this very difficult.

Data collection personnel were located at two positions. One member of the data collection team was stationed at the camera to ensure that the equipment was operating properly. This person also counted vehicles that passed the data collection station. Two other members of the data collection team drove downstream of the camera setup. The first member of the team was designated as the observer. This person had the responsibility of attempting to correctly match passing vehicles to the images that were transmitted to the laptop. The second member of the data collection team determined whether the observer correctly identified the vehicle as it passed.

\section{Focus Groups}

Subsequent to the field data collection activities, groups of law enforcement personnel were interviewed during this study. The purpose of these focus groups was to determine if the officers felt that remote enforcement could be legally and practically implemented in Texas. The first focus group consisted of deputies from Harris County, Texas. These officers were actually involved in day-to-day enforcement of traffic laws. The second focus group consisted of Texas Department of Public Safety (DPS) personnel. These officers were in leadership positions within the DPS. 


\section{RESULTS}

\section{Field Study}

Maximum Effective Data Transmission Range

Based on the results of the field data collection activities, the maximum transmission range achieved with this particular prototype arrangement ranged from 0.8 to $2.4 \mathrm{~km}$ (0.5 to 1.5 miles). The distance achieved by location can be found in Table 2 . The observed variability may have depended on such factors as topography, meteorological variations, and the presence of adjacent electrical power lines.

\section{TABLE 2: Maximum Transmission Distance.}

\begin{tabular}{cc} 
Site & Maximum Transmission Distance \\
\hline 1 & $1.6 \mathrm{~km}$ \\
72 & $2.4 \mathrm{~km}$ \\
3 & $0.8 \mathrm{~km}$ \\
4 & $1.6 \mathrm{~km}$ \\
\hline
\end{tabular}

$1 \mathrm{~km}=0.6$ miles

The observed transmission ranges were believed to be insufficient for many long-term construction and maintenance zones, and would need to be increased. The use of more powerful wireless modems, larger antennas, or repeater stations at intermediate locations could overcome this shortcoming. Another type of wireless communication approach might also provide longer transmission lengths. However, these options were not evaluated as part of this demonstration effort.

\section{Matching Images to Downstream Vehicles}

The ability of a downstream observer to correctly match images with passing vehicles at the downstream location is critical to the overall technical feasibility of this proposed concept. If officers could not identify the vast majority of images sent from the upstream camera location, a remote system would not be particularly useful to the enforcement community. Table 3 summarizes the percentage of vehicles that were successfully identified by the downstream observer during the field tests. At all four sites, between 84 and 88 percent of the images could be matched with the correct vehicle by the data collection personnel. The distance between the camera and the downstream observer did not appear to significantly impact the ability of the observer to identify vehicles over the range of distances studied. It was believed that some of the unmatched vehicles may have turned off the main road at intermediate access points after being photographed, but prior to reaching the downstream observer. 
TABLE 3: Vehicle Identification Rate.

\begin{tabular}{ccc} 
Site & $\begin{array}{c}\text { View of Vehicle } \\
\text { (Front/Rear) }\end{array}$ & $\begin{array}{c}\text { \% Vehicles } \\
\text { Correctly Identified }\end{array}$ \\
\hline 1 & Front & $88 \%$ \\
2 & Front & $84 \%$ \\
3 & Front & $87 \%$ \\
4 & Rear & $88 \%$ \\
\hline
\end{tabular}

At sites 1,2, and 3, vehicles where photographed from the front. Vehicles were photographed from the rear at site 4 . The ability of the observer to identify the vehicle did not appear to change significantly depending on whether the observer viewed an image of the front or the rear of the vehicle.

\section{Data Transmission}

Researchers also investigated the data transmission between the camera and the downstream computer. At each site, the camera took more pictures than were successfully transmitted to the downstream computer. Table 4 shows the percentage of pictures that were successfully transmitted from the camera to the downstream computer. The table indicates a negative relationship between the number of pictures taken and the percentage transmitted. This may have been due to the combined capacity of the software and hardware. The system appeared to stop transmitting an image if a new image was collected while the first was being transmitted.

TABLE 4: Data Transmission Results.

\begin{tabular}{cccc} 
Site & $\begin{array}{c}\text { Images Taken } \\
\text { Per Hour }\end{array}$ & $\begin{array}{c}\text { Images Received } \\
\text { Downstream Per Hour }\end{array}$ & $\begin{array}{c}\text { Percent Successfully } \\
\text { Transmitted }\end{array}$ \\
\hline 1 & 226 & 139 & 62 \\
2 & 147 & 102 & 70 \\
3 & 550 & 65 & 12 \\
4 & 134 & 95 & 71 \\
\hline
\end{tabular}

This trend indicates the need to select a speed threshold such that a low number of vehicles would be photographed per unit of time. This would likely be a useful strategy in any event, as this would allow law enforcement to focus exclusively on the fastest vehicles in the traffic stream.

\section{Focus Groups}

After the field testing was completed, the remote enforcement system was demonstrated to representatives of several law enforcement organizations. These representatives provided insight into how actual enforcement agencies would utilize the remote enforcement system. Potential legal issues with implementation of the system were also discussed. 


\section{Harris County}

Overall, the Harris County deputies' impressions of the technology were favorable. They noted that the approach had potential merit not only in work zones, but also anywhere the roadway cross-section was restricted (such as on long bridges). The deputies' attempts to identify vehicles whose images were transmitted downstream were generally successful. It was noted that the black-and-white display image made vehicle identification slightly more difficult, but did not act as a major barrier to identification.

One of the deputies mentioned that he envisioned the application of this technology in conjunction with a dedicated task force consisting of several officers. One officer would monitor the downstream equipment and identify approaching vehicles that the additional officers positioned next to him would pull over and issue citations. He felt that the technology would allow more violators to be identified and processed with this technology than could be achieved with the traditional multiple-officer enforcement teams.

It was also mentioned that having the digital image of the vehicle could be useful during the issuance of violations if the driver disagreed with the officer about violating the law. The deputies also felt that the distance between the camera and where the officer was stationed should not exceed $1.6 \mathrm{~km}(1 \mathrm{mi})$. They felt that motorists would be less accepting of the system if distances were long. This could potentially limit work zone applications of the remote enforcement system.

A key issue raised by the deputies during their visit was the ability to monitor the actual video in real-time from the downstream laptop location. They were concerned that they would not be able to establish visual verification that a violator did indeed appear to be exceeding the speed limit. According to their comments, it would be necessary for the officer to establish probable cause (which the technology could then verify with the video image and imprinted speed data) upon which to stop the violator and issue the citation. The researchers asked whether continuous video tracking would be necessary for this purpose from the point of detecting a violation until the vehicle was pulled over. According to these deputies, that was not a critical issue. Rather, it was only necessary to have several seconds of real-time video feed that the officer could see and make a determination that the vehicle did appear to be exceeding the speed limit. It was felt that with proper training, an officer could eventually learn how vehicles traveling at various speeds (especially those traveling at excessive speeds) would look on the downstream monitor.

\section{Texas Department of Public Safety}

The representatives from the Texas DPS had a more cautious view of the system than the deputies from Harris County. The DPS representatives had concerns that they would not have a continuous visual tracking history from the time the vehicle is detected exceeding the speed limit until the officer apprehends the motorist. The DPS officers indicated that they could not be absolutely sure that they were ticketing the proper driver, even if the gap in visual tracking history was only one minute. They felt that continuous, real-time video was the only way to ensure a visual tracking history that could not be challenged in the courts.

The DPS representatives interviewed indicated that they felt that remote enforcement had limited applications in Texas. The officers stated that automated speed enforcement would be the best method to reduce their workload and improve safety. They felt that the most immediate application of this technology would come as a result of the passage of enabling legislation at the state level. The purpose of this enabling legislation would be to validate the use of the remote 
enforcement system, and also to make the registered owner of a vehicle liable in the event that the driver could not be identified.

\section{SUMMARY}

Work zones are a difficult and dangerous place for law enforcement personnel to enforce speed limits. Remote speed enforcement appears to offer law enforcement personnel a means of enforcing work zone speed limits outside of the confines of the actual temporary traffic control area. This study attempted to determine the feasibility of using remote enforcement in work zones. The major findings from this study were:

- Downstream observers could identify between 84 to 88 percent of vehicles based on transmitted images. The ability of the observer to identify a vehicle did not appear to be impacted by the distance between the camera and the downstream observer or whether the vehicle was photographed from the front or the back.

- The ability of the system to successfully transmit photographs to the downstream observer depended on the frequency with which photographs were taken. The evaluation appeared to indicate that the speed threshold should be set so as not to overload the combined hardware/software processing capabilities of the ASE system or the transmission rates of the wireless communication technology.. This improved the percentage of vehicles that were transmitted downstream successfully.

- Law enforcement officers felt that there may be some initial legal challenges to the use of this system until it had become accepted by the courts. Some officers felt that the system could be used in the existing legal structure, and would provide a safety benefit to enforcement personnel. However, other officers felt that some modifications, especially the inclusion of real-time video, would be necessary before the system could be used in Texas. Some of the DPS officers believed that additional enabling legislation would be required to permit the use of the system at the state level. The officers did not come to a consensus regarding the legal viability of the system. They felt that it would need to be tested in the courts prior in order to assess the legal ramifications of the system.

This study provided an initial examination of the concept of remote enforcement of traffic laws in work zones. Remote enforcement overcomes many of the legal barriers that prevent the use of automated enforcement, and also provides the potential for officers to safely enforce work zones. However, the law enforcement officer comments indicated that several improvements needed to be made before the system could be used in Texas.

\section{RECOMMENDATIONS FOR FURTHER DEVELOPMENT}

This study showed that the prototype system may provide a safety benefit to law enforcement officers engaged in work zone speed enforcement. However, there are several potential improvements that could be made to the system to improve its flexibility and functionality. Potential future improvements could include:

- Improved communications systems: The communications system tested had an observed maximum range of $2.4 \mathrm{~km}$ (1.5 miles). Many work zones exceed this distance. Longer ranges must be obtained before the system could be applied to a wide variety of sites. 
Extendable antennas or different types of communication may be needed to increase the flexibility of the system.

- Real-time video: Several law enforcement officers felt that real-time video should be provided so that they could visually verify that a vehicle appeared to be exceeding the speed limit. This would require that the communications bandwidth be increased.

- Provision of color images: Officers commented that color images would aid in the recognition of violators.

- Provision of two-way communications: The downstream observer could not modify settings at the camera station with the prototype. Any future models should allow the downstream user to change the speed threshold, aim the camera, and focus the camera without actually returning to the upstream site.

- Improvements to system portability: Installation of the prototype system proved to be time-consuming, frequently taking more than 2 hours. In order for the system to be used by the enforcement community, this time needs to be reduced. It may be possible to incorporate the system into a trailer that could be towed to the site. This trailer could have all of the equipment hardwired together, and include and extendable antenna in order to facilitate longdistance communications. If motorists become familiar with these trailers, it is possible that the presence of these trailers may have some speed reduction benefits in the work zone. Other advance work zone signing, noting the use of camera enforcement, may also need to be developed so as to increase driver awareness of the system and improve the "halo" effect of the enforcement activities.

\section{ACKNOWLEDGEMENTS}

This research was sponsored by the Texas Department of Transportation. The contents of this paper reflect the views of the authors, who are responsible for the facts and accuracy of the data presented herein. The contents do not necessarily reflect the views of the Texas Department of Transportation.

A number of individuals provided their support during this study. Scott Patterson of LaserCraft provided the automated speed enforcement equipment. Leonard Ruback of TTI developed the data transmission programs, an provided extensive support in the initial testing and debugging of the system. The authors would also like to thank the representatives from the Harris County Sheriff's Department and the Austin headquarters of the Department of Public Safety for their input during the focus group meetings.

\section{REFERENCES}

1. Fatality Analysis Reporting System. National Highway Traffic Safety Administration, http://www-fars.nhtsa.dot.gov, accessed July 2, 2001.

2. Richards, S.H., R.C. Wunderlich, and C.L. Dudek. Field Evaluation of Work Zone Speed Control Techniques. In Transportation Research Record 1035. Transportation Research Board, National Research Council, Washington, D.C., 1985.

3. Richards, S.H. and C.L. Dudek. Implementation of Work-Zone Speed Control Measures. In Transportation Research Record 1086. Transportation Research Board, National Research Council, Washington, D.C., 1986. 
4. Freedman, M., A.F. Williams, and A.K. Lund. Public Opinion Regarding Photo-Radar. In Transportation Research Record 1270. Transportation Research Board, National Research Council, Washington, D.C., 1990.

5. Turner, S., and A.E. Polk. Overview of Automated Enforcement in Transportation. ITE Journal, Vol. 68, No. 6, June 1998.

6. Oei, J.L. Automatic Speed Management in the Netherlands. In Transportation Research Record 1560. Transportation Research Board, National Research Council, Washington, D.C., 1996.

7. Elvik, R. Effects on Accidents of Automatic Speed Enforcement in Norway. In Transportation Research Record 1595. Transportation Research Board, National Research Council, Washington, D.C., 1997.

8. Transportation Research Board. Special Report 254: Managing Speed: Review of Current Practice for Setting and Enforcing Speed Limits. Transportation Research Board, National Research Council, Washington, D.C., 1998.

9. Bloch, S.A. Comparative Study of Speed Reduction Effects of Photo-Radar and Speed Display Boards. In Transportation Research Board Annual Meeting Compendium of Technical papers CD-ROM, 1998.

10. Lynn, C.W., W.S. Ferguson, and N.J. Garber. Feasibility of Photo-Radar for Traffic Speed Enforcement in Virginia. In Transportation Research Record 1375. Transportation Research Board, national Research Council, Washington, D.C., 1992.

11. Fitzpatrick, K. and T. Urbanik. Automated Enforcement-Legal Issues. Technical Memorandum to the Texas Department of Transportation, Texas Transportation Institute, 1990. 12. Peters, E. Red-light Cameras Violate Motorists' Privacy. Tallahassee Democrat. June 15, 2001.

13. McKinstry, L. Speed Scam. The Spectator. June 16, 2001. 